\title{
Influence on collateral flow of recanalising chronic total coronary occlusions: a case-control study
}

\author{
T Pohl, P Hochstrasser, M Billinger, M Fleisch, B Meier, C Seiler
}

\begin{abstract}
Objective-To assess the effect of recanalisation on collateral flow in a case-control study in patients with and without chronic total coronary occlusions.

Design-In 54 patients undergoing percutaneous transluminal coronary angioplasty (PTCA) (mean (SD) age 61 (6) years), coronary collateral flow was measured by intracoronary pressure or Doppler guide wires at the end of repeated balloon occlusions. Coronary collateral flow index (collateral flow relative to normal antegrade flow) during the first two balloon inflations in 27 patients with a chronic total occlusion (occlusion group) was compared with that of 27 patients matched for age, sex, and collateral flow index at the first occlusion and with a coronary artery diameter stenosis $\leqslant 80 \%$ (stenosis group).

Results-Following revascularisation, collateral flow index decreased in 17 of the patients in the occlusion group (63\%) and in eight of the patients in the stenosis group (30\%) (p = 0.03 between groups). The overall change of collateral flow index between the first and the second balloon occlusion was $-0.04(0.01)$ in the occlusion group $(\mathrm{p}=0.07$ for paired comparison; from 0.29 $(0.17)$ to $0.25(0.14)$ ), and $+0.02(0.06)$ in the stenosis group ( $\mathrm{p}=0.06$ for paired comparison; from $0.27(0.13)$ to $0.30(0.15))$. The trend to collateral enhancement in the stenosis group differed significantly from the occlusion group $(\mathrm{p}=0.01)$.

Conclusions-While repeated coronary balloon occlusions induce collateral recruitment in the majority of patients with moderate stenoses, recanalisation of chronic total coronary occlusions is more often associated with collateral flow reduction. A later decrease in collateral flow by involution of collateral channels cannot be excluded by this study but has not been reported so far.

(Heart 2001;86:438-443)
\end{abstract}

Keywords: coronary collateral circulation; coronary occlusion; revascularisation; collateral damage

In patients with coronary artery disease, the collateral circulation supplying myocardium distal to a stenosis or occlusion can minimise infarct size, reduce evolution of left ventricular aneurysm formation, improve ventricular function, and lead to improved survival. ${ }^{1-3}$ More than one third of patients with significant coronary artery disease present with chronic total coronary occlusions. ${ }^{45}$ Despite the fact that chronic total occlusions are the prime contraindication for angioplasty, they account for $10 \%$ of angioplasty interventions..$^{5-7}$

There have been case reports ${ }^{8}{ }^{9}$ documenting a possible negative effect of recanalisation of total coronary occlusions on collateral flow. In an uncontrolled study including 18 patients, a reduction of myocardial perfusion in segments receiving collateral flow was found after recanalisation. ${ }^{10}$ Collateral perfusion was assessed using semiquantitative intracoronary contrast echocardiography (visual score for video density), a rather imprecise method for assessing collateral flow.

There has been speculation about the reason for a negative effect of recanalisation on collateral flow. Thrombotic material may be mobilised by the procedure to disturb the downstream circulation, ${ }^{89}$ or vasoactive substances may be released through the intervention to cause a reduction in collateral flow. ${ }^{8}$

In the present investigation we tested the influence of recanalisation of coronary occlusions on the collateral circulation using intracoronary measurements, and compared the results with those in matched cases of coronary stenosis.

\section{Methods}

PATIENTS

We studied 54 patients with coronary artery disease undergoing percutaneous transluminal coronary angioplasty (PTCA) with at least two subsequent one minute balloon occlusions. Their mean (SD) age was 61 (6) years. Nine were women and 55 were men. There were no cases of $\mathrm{Q}$ wave myocardial infarction. Patients were selected retrospectively and divided into two groups: a group with structural or functional chronic total coronary occlusion (for more than one month; thrombolysis in myocardial infarction trial (TIMI) flow grading of $\leqslant 1$ ) (occlusion group, $n=27$ ); and a group with diameter stenoses of $\leqslant 80 \%$ (stenosis group, $\mathrm{n}=27$ ). The two groups were matched for age, sex, and collateral flow index (see below) at the end of the first coronary occlusion. The data were derived from separately reported prospective studies, ${ }^{11-14}$ approved by the local ethics committee and with informed consent of the patients.

\section{CORONARY ANGIOGRAPHY}

Patients underwent left heart catheterisation, including biplane left ventricular angiography and coronary angiography for diagnostic purposes. Coronary artery stenoses were assessed quantitatively as per cent diameter reduction, using the guiding catheter for calibration. Aortic pressure was measured using the 6 French angioplasty guiding catheter.

COLLATERAL FLOW MEASUREMENTS

Coronary collaterals were assessed using intracoronary pressure $(n=46)$ or Doppler 
Table 1 Patient characteristics

\begin{tabular}{llll}
\hline & Occlusion group & Stenosis group & p Value \\
\hline $\mathrm{n}$ & 27 & 27 & \\
Male & $23(85 \%)$ & $22(81 \%)$ & $\mathrm{NS}$ \\
Age (years) & $62(9)$ & $60(9)$ & $\mathrm{NS}$ \\
Body mass index $\left(\mathrm{kg} / \mathrm{m}^{2}\right)$ & $28(3)$ & $27(3)$ & $\mathrm{NS}$ \\
Mean blood pressure $(\mathrm{mm} \mathrm{Hg})$ & $93(9)$ & $97(5)$ & $\mathrm{NS}$ \\
Heart rate (beats/min) & $72(9)$ & $71(11)$ & $\mathrm{NS}$ \\
Coronary risk factors & & & \\
$\quad$ Diabetes mellitus & $8(30 \%)$ & $2(7 \%)$ & 0.04 \\
$\quad$ Hypertension & $9(33 \%)$ & $4(15 \%)$ & $\mathrm{NS}$ \\
Smoking & $11(41 \%)$ & $13(48 \%)$ & $\mathrm{NS}$ \\
Obesity & $6(22 \%)$ & $6(22 \%)$ & $\mathrm{NS}$ \\
$\quad$ Hypercholesterolaemia & $12(44 \%)$ & $16(59 \%)$ & $\mathrm{NS}$ \\
$\quad$ Family history of CAD & $13(48 \%)$ & $10(37 \%)$ & $\mathrm{NS}$ \\
Drug treatment & & & \\
$\quad$ Calcium antagonists & $6(22 \%)$ & $1(4 \%)$ & 0.04 \\
$\quad$ Blockers & $15(56 \%)$ & $15(56 \%)$ & $\mathrm{NS}$ \\
Nitrates & $12(44 \%)$ & $9(33 \%)$ & $\mathrm{NS}$ \\
Aspirin & $22(82 \%)$ & $25(93 \%)$ & NS \\
Statins & $4(15 \%)$ & $9(33 \%)$ & NS \\
ACE inhibitors & $5(19 \%)$ & $4(15 \%)$ & NS \\
\hline
\end{tabular}

Values are mean (SEM) or $\mathrm{n}(\%)$.

$\mathrm{ACE}$, angiotensin converting enzyme inhibitors; $\mathrm{CAD}$, coronary artery disease.

Table 2 Angiographic data

\begin{tabular}{llll}
\hline & Occlusion group & Stenosis group & p Value \\
\hline $\begin{array}{l}\text { Number of vessels diseased } \\
\text { Vessel }\end{array}$ & $1.7(0.6)$ & $1.9(0.9)$ & NS \\
LAD & $11(41 \%)$ & $16(59 \%)$ & NS \\
LCx & $8(30 \%)$ & $2(7 \%)$ & NS \\
RCA & $5(19 \%)$ & $6(22 \%)$ & NS \\
Per cent diameter stenosis & $98(2)$ & $71(13)$ & $<0.0001$ \\
LV ejection fraction $(\%)$ & $64(10)$ & $69(10)$ & NS \\
\hline
\end{tabular}

Values are mean (SEM) or $\mathrm{n}(\%)$.

$\mathrm{LAD}$, left anterior descending coronary artery; LCx, left circumflex coronary artery; LV, left ventricular; RCA, right coronary artery.

$(\mathrm{n}=8)$ guide wires for PTCA. The 0.014 inch fibreoptic pressure guide wire (WaveWire, Endosonics, Rancho Cordova, California, USA) was set at zero, calibrated, advanced through the guiding catheter, normalised for aortic pressure at the ostium of the coronary artery, and positioned distal to the stenosis to be dilated. The pressure derived collateral flow index (no units) was determined by simultaneous measurement of mean aortic pressure $\left(\mathrm{P}_{\mathrm{ao}}\right.$, $\mathrm{mm} \mathrm{Hg}$ ) and the distal intracoronary pressure at the end of a one minute balloon occlusion (coronary wedge pressure, $\mathrm{P}_{\text {occl }}, \mathrm{mm} \mathrm{Hg}$ ) (figs 1 and 2). Central venous pressure (CVP) was estimated to be $5 \mathrm{~mm} \mathrm{Hg}$. Collateral flow index was calculated as $\left(\mathrm{P}_{\text {occl }}-\mathrm{CVP}\right)$ divided by $\left(\mathrm{P}_{\mathrm{ao}}-\mathrm{CVP}\right) .{ }^{12}{ }^{15} \mathrm{We}$ showed that the intracoronary pressure was not reliable in patients with a left ventricular end diastolic pressure of $\geqslant 15 \mathrm{~mm} \mathrm{Hg}$ before vessel occlusion. ${ }^{16}$ In this case, intracoronary flow velocity measurements were used to assess the collateral flow index $(\mathrm{n}=8)$. Velocity derived collateral flow index measurements were performed using a 0.014 inch Doppler guide wire with a $12 \mathrm{MHz}$ piezoelectric crystal at its tip (FlowWire ${ }^{\circledR}$, Endosonics, Rancho Cordova, California, USA). The validation of this wire has been described previously. ${ }^{17}$ Velocity derived collateral flow index was determined as the ratio of flow velocitytime integral distal to the occluded stenosis divided by the baseline flow velocity integral obtained at the same site after PTCA and following reactive hyperaemia. ${ }^{12}$ Bidirectional flow velocity signals were added to obtain total collateral flow velocity. The collateral flow index expresses collateral flow relative to normal antegrade flow in a patent epicardial vessel. The two methods used to assess collateral flow index have been validated previously. ${ }^{12}$

Angiographic collateral degree was determined according to the extent of the epicardial coronary artery filling via collaterals with contrast medium from the contralateral side before PTCA: $0=$ no filling of the distal vessel; $1=$ small side branches filled; $2=$ major side branches filled; 3 = main vessel filled.

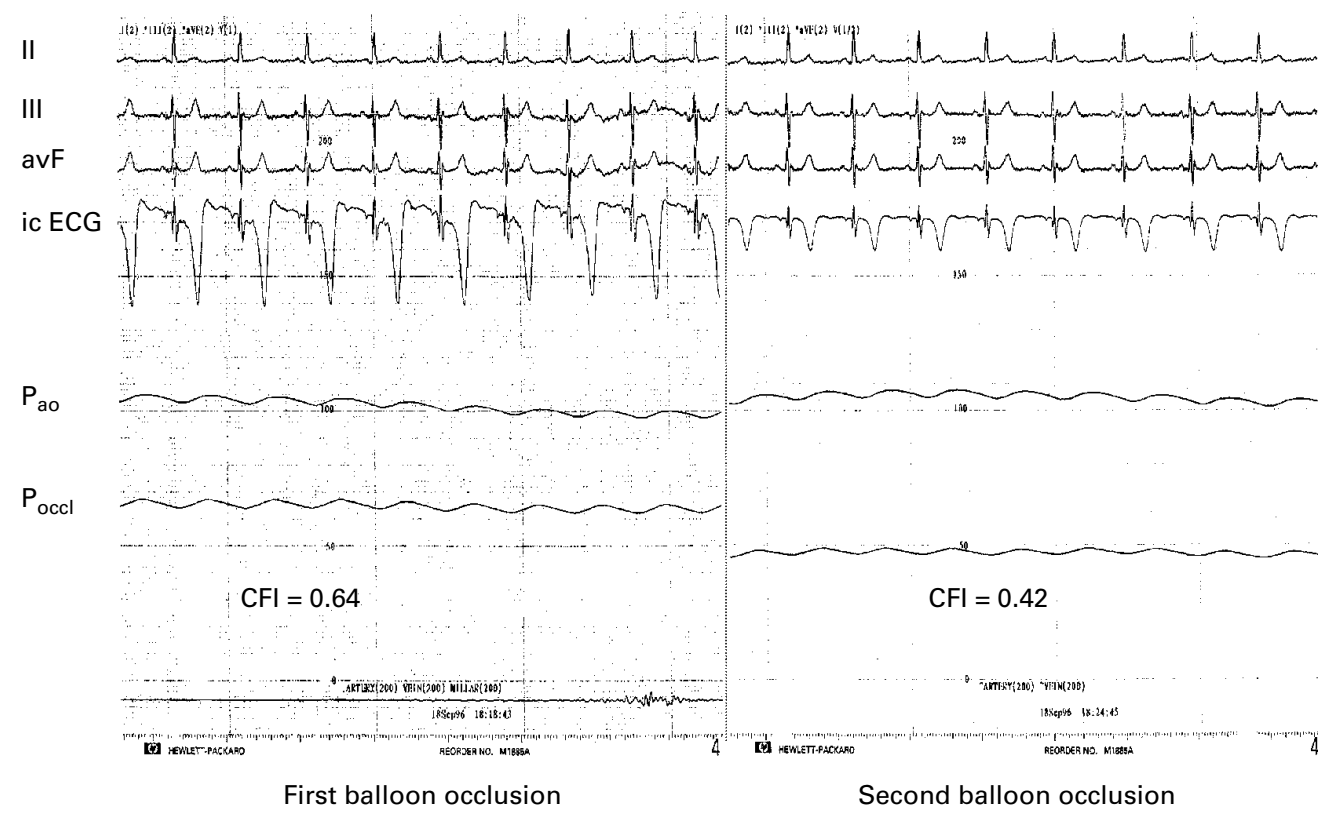

Figure 1 Simultaneous tracings of four ECG leads and mean aortic $\left(P_{a d}\right)$ and distal intracoronary pressure $\left(P_{\text {occ }}\right)$ after the end of the first (left) and second balloon occlusion (right). Central venous pressure (CVP) is estimated to be $5 \mathrm{~mm} H \mathrm{Hg}$. Collateral flow index $(C F I)$ is calculated as $\left(P_{\text {ocl }}-C V P\right)$ divided by $\left(P_{a p}-C V P\right)$. Collateral flow index at the end of the second balloon occlusion was reduced to 0.42 from 0.64 at the first occlusion in this patient with chronic total coronary occlusion. Calibration amplitude was reduced by $50 \%$ for the intracoronary ECG on the right panel. 


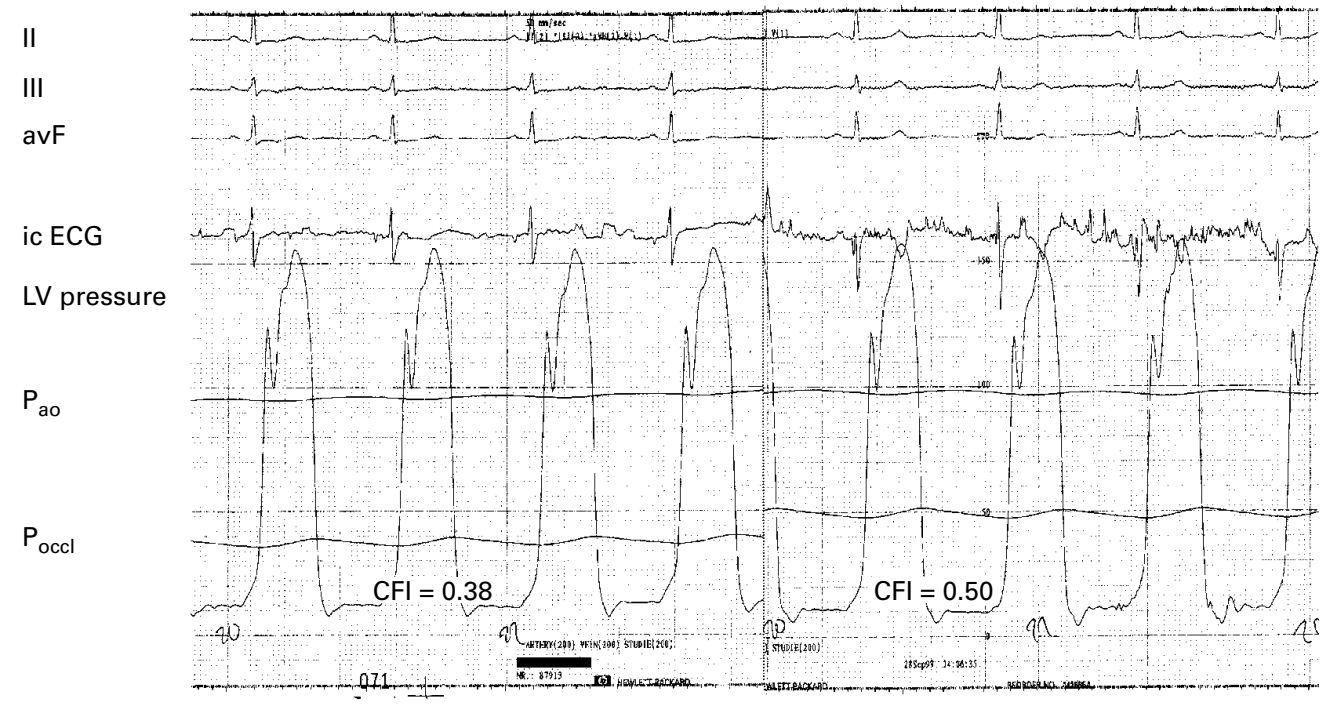

First balloon occlusion

Second balloon occlusion

Figure 2 Assessment of collateral flow index (CFI) as described in fig 1. The index was increased at the second balloon occlusion to 0.50, from 0.38 at the first occlusion, in a patient with a moderately severe stenosis of a coronary artery. LV, left ventricular.

DATA ANALYSIS

Collateral flow index was assessed at the end of subsequent one minute balloon occlusions. The first collateral flow index was measured at the end of the first one minute balloon occlusion of the coronary lesion; the second and final index was assessed at the end of the next one minute balloon occlusion. The change in the index at these subsequent balloon occlusions ( $\triangle \mathrm{CFI}$ ) was calculated as the index at the second balloon occlusion minus that at the first.

\section{STATISTICAL ANALYSIS}

The unpaired Student $t$ test was used for comparison of continuous variables and the $\chi^{2}$ test for comparison of categorical variables among the two study groups. The paired Student $t$ test was used for comparison of $\Delta C F I$. Significance was defined at a probability value of $\mathrm{p}<0.05$.

\section{Results}

PATIENT CHARACTERISTICS

There were no differences between the study groups with regard to sex, age, body mass index, mean blood pressure, or heart rate (table 1).

Table 3 Collateral flow data and changes in collateral flow index between first and second occlusion

\begin{tabular}{llll}
\hline & Occlusion group & Stenosis group & p Value \\
\hline $\mathrm{n}$ & 27 & 27 & \\
Sufficient collaterals & $18 / 27$ & $5 / 27$ & 0.0002 \\
Angiographic collateral degree & $2.3(0.8)$ & $0.8(0.7)$ & 0.0001 \\
CFI at first occlusion & $0.29(0.17)$ & $0.27(0.13)$ & $\mathrm{NS}$ \\
Decreased CFI & $17(63 \%)$ & $8(30 \%)$ & 0.03 \\
Increased CFI & $10(37 \%)$ & $17(63 \%)$ & 0.03 \\
Unchanged CFI & 0 & $2(7 \%)$ & $\mathrm{NS}$ \\
$\begin{array}{l}\text { Time from start of intervention to first CFI } \\
\quad \text { measurement (min) }\end{array}$ & $21(9)$ & $19(14)$ & $\mathrm{NS}$ \\
\hline
\end{tabular}

Values are mean (SEM) or $\mathrm{n}(\%)$.

${ }^{\star}$ No intracoronary ECG ST changes during occlusion.

CFI, collateral flow index.
CLINICAL DATA

There were four previous non-transmural myocardial infarctions in each of the groups. Patients in the occlusion group were significantly more likely to have diabetes mellitus than those in the stenosis group $(30 \% v 7 \%$, table 1). There was no difference between the groups for other cardiovascular risk factors. More patients in the occlusion group than in the stenosis group received calcium antagonists $(22 \% v 4 \%)$. Treatment with $\beta$ blockers, nitrates, acetylsalicylic acid, statins, and angiotensin converting enzyme inhibitors did not differ between the groups (table 1).

ANGIOGRAPHIC DATA

The occlusion and stenosis groups did not differ in terms of the angiographic classification of coronary artery disease except for the severity of the stenosis undergoing PTCA (table 2). The left ventricular ejection fraction was $64 \%$ in the occlusion group and $69 \%$ in the stenosis group (table 2).

COMPARISON OF COLLATERAL FLOW DURING THE FIRST TWO BALLOON OCCLUSIONS

The angiographic collateral degree was 2.3 $(0.8)$ in the occlusion group and $0.8(0.7)$ in the stenosis group, respectively. Collateral flow index at the first occlusion was $0.29(0.2)$ in the occlusion group and $0.27(0.1)$ in the stenosis group; this decreased to $0.25(0.14)$ at the second balloon occlusion in the occlusion group, and increased to $0.30(0.15)$ in the stenosis group (fig 3; $\mathrm{p}=0.1$ for difference at the second balloon occlusion). Immediately after recanalisation, collateral flow index decreased (fig 1) in 17 of the 27 patients in the occlusion group, whereas it decreased in only eight of the 27 patients in the stenosis group (63\% v 30\%; $\mathrm{p}=0.03$ between groups, table 3 and fig 3). In 10 patients $(37 \%)$ in the occlusion group, collateral flow index increased whereas it 

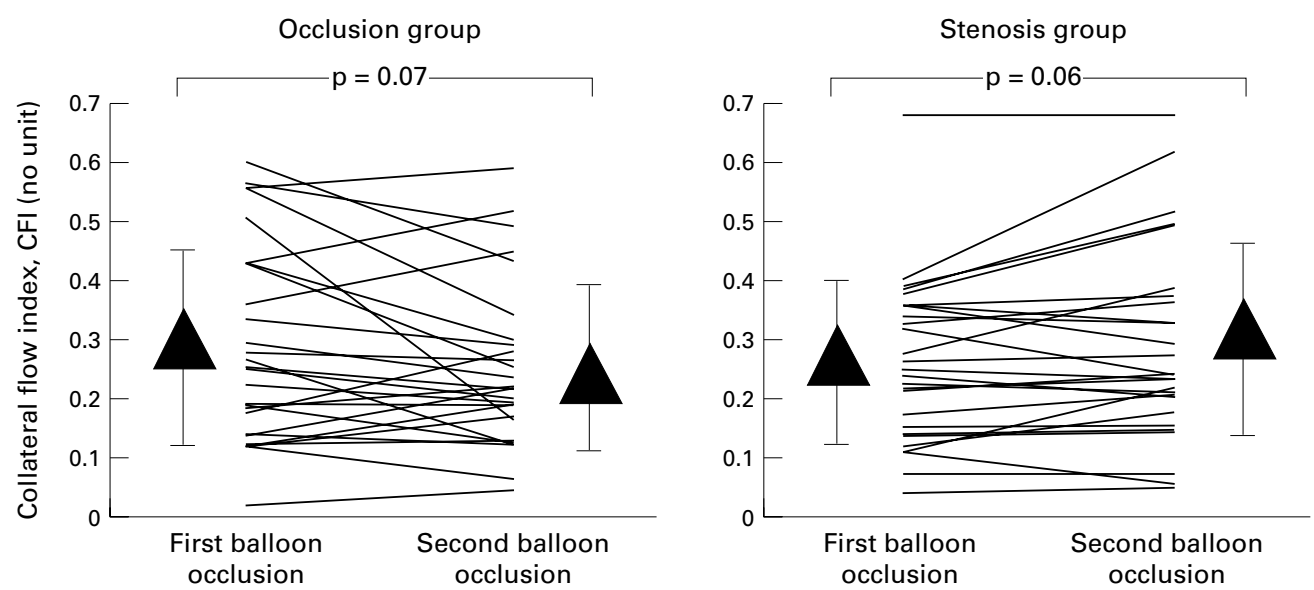

Figure 3 Individual values with mean and standard deviation for collateral flow index (CFI) at the end of the first two vessel occlusions in patients with total occlusions and in patients with coronary stenoses.

increased in $17(63 \%)$ of the stenosis group (fig 2). Collateral flow index remained unchanged in two patients in the stenosis group (table 3).

Mean $\triangle$ CFI was $-0.04(0.01)(\mathrm{p}=0.07$, for paired comparison) in the occlusion group, and $+0.02(0.06)(\mathrm{p}=0.06)$ in the stenosis group. Unpaired comparison of $\triangle \mathrm{CFI}$ showed a significant difference between the two groups $(\mathrm{p}=0.01$, fig 4$)$.

\section{Discussion}

This case-control study in patients with similar baseline collateral flow to a coronary region undergoing revascularisation showed that individuals with chronic total occlusions had an overall decrease in collateral flow of $14 \%$ following recanalisation, whereas those with mild to moderate stenotic lesions had an overall recruitment in collateral flow of $7 \%$ at the second of two subsequent balloon occlusions.

ROLE OF COLLATERALS IN CORONARY OCCLUSIONS

A total coronary occlusion happening insidiously is probably collateralised. The final occlusion occurs without myocardial infarction or with only limited infarction. If the collateral flow to the occluded vascular region amounts

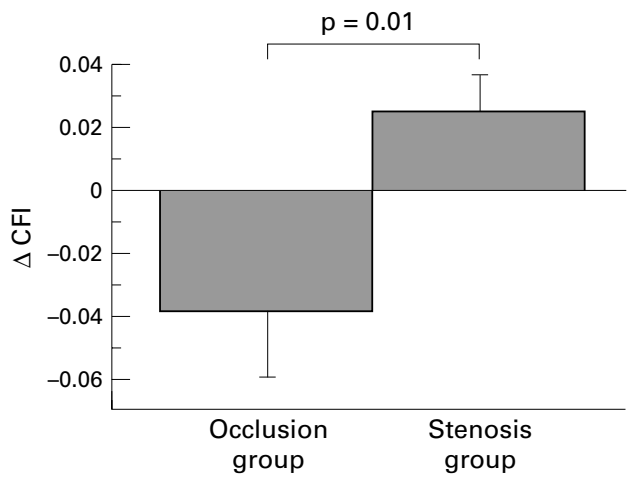

Figure 4 Difference in collateral flow index ( $\triangle C F I)$ between the first and the second balloon occlusion. Unpaired comparison of $\triangle C F I$ (value of collateral flow index at second balloon occlusion minus value at first balloon occlusion) showed a significant difference between the occlusion group and the stenosis group $(p=0.01)$. to more than $25 \%$ of the normal flow, ${ }^{12}{ }^{18}$ there might not even be angina at rest, and myocardial function in the collateral dependent area will be maintained. ${ }^{19}$ However, effort induced angina brings such patients to percutaneous revascularisation. ${ }^{20-22}$ Opening occluded coronary arteries, especially the left anterior descending, may improve symptoms, obviate the need for bypass surgery, and even improve prognosis. ${ }^{23-25}$ In the light of the still relatively low technical success rate and only moderate clinical improvement to be expected with recanalisation, moderation in attempting PTCA in these cases is called for. ${ }^{26}$ Moreover, the risk of restenosis and reocclusion is increased in the presence of the well developed collaterals typical of chronic coronary occlusions subjected to PTCA. ${ }^{27-32}$ Reocclusion may cause clinical events in the case of intervention related damage to collaterals. ${ }^{8}$ The present study investigated whether damage to collaterals following revascularisation occurs in the form of impaired collateral recruitability, represented by a decrease in collateral flow on repeated coronary occlusions. Disappearance of angiographic collaterals after recanalisation is a marker of the success of the intervention. ${ }^{33}$ However, this cannot be interpreted as damage to collaterals caused by the PTCA. It is related simply to the diminishing pressure gradient between the collateral receiving artery and the collateral supplying artery upon the restoration of antegrade flow. Nevertheless, impairment of recruitability of collaterals is conceivable and may be transient, mediated by a release of constrictive mediators by the recanalisation. It may also be permanent, resulting from obstruction of the collateral channels by macro- and microemboli. Finally, loss of collaterals may be late, resulting from atrophy of no longer required channels. This would be only slowly reversible in the case of later reocclusion. Case reports documenting immediate recruitability of collaterals several years after they had been taken out of use by successful recanalisation ${ }^{34} 35$ do not exclude this latter mechanism. They merely show cases where it did not apparently play a role. 
BEHAVIOUR OF COLLATERALS FOLLOWING RECANALISATION OF OCCLUSIONS

In the setting of an uncontrolled study investigating the behaviour of collaterals after total occlusion revascularisation, patients with high initial collateral flow are likely to be selected owing to the direct relation between stenosis severity and collateral flow. Among more than 400 patients examined for collateral assessment at our laboratory, the 40 with collateralised total occlusions undergoing revascularisation had a collateral flow index sufficient to prevent myocardial ischaemia during vessel obstruction $(\geqslant 0.25)$ in $72 \%$, whereas the patients with non-occlusive stenotic lesions had a collateral flow index of $<0.25$ in $71 \%$. It is possible that a high baseline collateral flow index is associated with a more pronounced reduction in flow following recanalisation than recanalysed occlusions with a lower baseline collateral flow index. Thus the phenomenon of collateral flow decrease may be amplified by greater changes in driving forces across the collaterals after the restoration of antegrade flow: a greater degree of post-PTCA, flow related collateral vasoconstriction-owing to a more pronounced reduction in intercoronary driving pressure in initially extensive versus sparse collaterals - may affect collateral flow alterations on biophysical grounds. To account for these possibilities, we used a case-control study design in our investigation, and patients with and without occlusions were matched for baseline collateral flow index.

Little is known about the magnitude or timing of collateral flow changes following restitution of antegrade flow in total occlusions. Contrast echocardiographic imaging of the collateralised myocardium has shown that the collateral supplied microcirculation (about $10 \mu \mathrm{m}$ in diameter ${ }^{36}$ ) persists for at least 15 minutes after recanalisation of the occlusion, whereas angiographically visible - that is, epicardial collaterals (about $100 \mu \mathrm{m}$ )-disappear immediately. ${ }^{1033}$ As collateral flow index measures the functional relevance of collaterals, it reflects collateralised myocardial perfusion more reliably than angiography; this has been supported very recently by the demonstration of a close, direct association between quantitatively assessed myocardial contrast echocardiography and simultaneously obtained collateral flow index. ${ }^{37}$ Thus the time window of the few minutes between the first and second balloon occlusion in our study suggests that the fall in collateral flow index cannot provide information about a possible late change. For instance, collateral opening during repetitive episodes of ischaemia in our controls (collateral recruitment) may not have been at its maximum when assessed at the second instead of at a third or fourth balloon occlusion. ${ }^{38}$ During a time window of 15 minutes at the most, ${ }^{10}$ recanalised total occlusions seem to be associated with collateral derecruitment rather than with recruitment, as seen in non-occlusive stenoses during repetitive ischaemia. Published reports indicate that this collateral derecruitment is a temporary dysfunction ${ }^{33} 39$ and not a reflection of permanent damage to the collaterals. ${ }^{9}$
According to our results there seems to be a risk of acute collateral impairment following recanalisation of total occlusion, as this was documented in 17 of the 27 patients with a decreasing collateral flow index $(p=0.0005$ for paired comparison), although the overall difference did not reach statistical difference (fig 3).

STUDY LIMITATIONS

Aside from the limitations discussed above, possible inaccuracies related to the technique used for collateral assessment need to be mentioned. CVP for the calculation of pressure derived collateral flow index was an estimate instead of a direct measurement in our patients. We measured CVP in 50 other patients in our institution (not included in the present study) and found that collateral flow index calculated by measured CVP was equal to 1.02 times collateral flow index computed by assumed CVP minus $0.03\left(r^{2}=0.92\right.$, standard error of estimate $=0.04) .{ }^{40}$ Furthermore, even if the error were larger it would be evenly distributed among the two study groups, as the pressure derived collateral flow index was used to a similar extent in patients with $(n=22)$ and without ( $n=24$ ) occlusions. Thus the patients undergoing Doppler derived collateral flow index measurements were almost identically dispersed between the two groups, and the influence of possible errors related to the Doppler derived versus the pressure derived technique to gauge collateral flow would have influenced the results of both groups similarly. These considerations are only of theoretical relevance as the standard error of the estimate between pressure derived and Doppler derived collateral flow index determinations is quite small (0.08), and because both values are interchangeable. ${ }^{12}$ The fact that the collateral flow index is known to be at variance with qualitative measurements of angiographic collateral degree and also with ECG signs of myocardial ischaemia obtained during coronary occlusion $^{12}$ is, however, illustrated by the intergroup differences in those variables, despite similar collateral flow index values. It is uncertain whether this discrepancy influenced the degree of collateral recruitment in the stenosis group. Owing to the retrospective design of the study, with one minute instead of two to three minute balloon occlusions, ${ }^{38}$ collateral recruitment could not be determined entirely appropriately. However, this indicates that the difference between collateral flow attenuation in the occlusion group and recruitment in the stenosis group may even have been underestimated in our investigation. Conversely, the study only pertains to the first minutes after either a recanalisation of a chronic total occlusion or a stenosis of a previously patent vessel. No prediction can be made about later effects of recanalisation or stenosis reduction on collaterals.

CONCLUSIONS

While repetitive coronary balloon inflations induce collateral recruitment in the majority of patients with moderate stenoses, recanalisation 
of chronic total coronary occlusions is more often associated with collateral flow reduction. A later decrease in collateral flow by involution of collateral channels cannot be excluded by this study but has not been reported so far.

1 Habib GB, Heibig J, Forman SA, et al. Influence of coronary collateral vessels on myocardial infarct size in humans. Results of phase I thrombolysis in myocardial infarction (TIMI) trial. The TIMI investigators. Circulation 1991;83:739-46.

2 Hirai T, Fujita $M$, Nakajima $H$, et al. Importance of collateral circulation for prevention of left ventricular aneurysm eral circulation for prevention of left ventricular aneurysm formation

3 Hansen J. Coronary collateral circulation: clinical significance on survival in patients with coronary artery occlusion. Am Heart f 1989;117:290-5.

$4 \mathrm{Kahn} \mathrm{JK}$. Angiographic suitability for catheter revascularization of total coronary occlusions in patients from a community hospital setting. Am Heart f 1993;126:561-4.

5 Delacretaz E, Meier B. Therapeutic strategy with total coronary artery occlusions. Am f Cardiol 1997;79:185-7.

6 Gray D, Sivananthan U, Verma S, et al. Balloon angioplasty of totally and subtotally occluded coronary arteries: results using the hydrophillic terumo radifocus guidewire $M$ (glidewire). Cathet Cardiovasc Diagn 1993;30:293-9.

7 Meier B. Coronary angioplasty in chronic total occlusion. Rev Port Cardiol 1999;18(suppl 1):I55-60.

8 Pijls NH, Bracke FA. Damage to the collateral circulation by PTCA of an occluded coronary artery. Cathet Cardiovasc Diagn 1995;34:61-4.

9 Waser M, Kaufmann U, Meier B. Mechanism of myocardial infarction in a case with acute reocclusion of a recanalized chronic total occlusion: a case report. F Intervent Cardio 1999;12:137-40.

10 Petronio AS, Baglini R, Limbruno U, et al. Coronary collateral circulation behaviour and myocardial viability in chronic total occlusion treated with coronary angioplasty. Eur Heart $\mathcal{F}$ 1998;19:1681-7.

11 Seiler C, Fleisch M, Meier B. Direct intracoronary evidence of collateral steal in humans. Circulation 1997;96:4261-7.

12 Seiler C, Fleisch M, Garachemani A, et al. Coronary collateral quantitation in patients with coronary artery disease using intravascular flow velocity or pressure measurements. f Am Coll Cardiol 1998;32:1272-9.

13 Seiler C, Fleisch M, Billinger M, et al. Simultaneous intracoronary velocity- and pressure-derived assessment of adenosine-induced collateral hemodynamics in patients with one- to two-vessel coronary artery disease. $7 \mathrm{Am}$ Coll with one- to two-vessel coro

14 Fleisch M, Billinger M, Eberli FR, et al. Physiologically assessed coronary collateral flow and intracoronary growth factor concentrations in patients with 1- to 3-vessel coronary artery disease. Circulation 1999;100:1945-50.

15 Pijls NH, van Son JA, Kirkeeide RL, et al. Experimental basis of determining maximum coronary, myocardial, and collateral blood flow by pressure measurements for assessing functional stenosis severity before and after percutaneous transluminal coronary angioplasty. Circulation 1993;87 1354-67.

16 de Marchi S, Pohl T, Fleisch M, et al. Influence of left ventricular filling on coronary collateral perfusion-pressure [abstract]. 7 Am Coll Cardiol 2000;35:377.

17 Doucette JW, Corl PD, Payne HM, et al. Validation of a Doppler guide wire for intravascular measurement of coronary artery flow velocity. Circulation 1992;85:1899911.

18 Pijls NH, Bech GJ, el Gamal MI, et al. Quantification of recruitable coronary collateral blood flow in conscious humans and its potential to predict

19 Seiler C, de Marchi S, Lipp E, et al. Regional left ventricular function during coronary occlusion in relation to quantitatively assessed collateral supply to this area [abstract]. Eu Heart $\mathcal{f} 2000 ; 21$ (suppl):28.
20 Baim DS, Kuntz RE. Coronary angioplasty. Is surgical standby needed? $7 A M A$ 1992;268:780-1.

21 Ellis SG, Roubin GS, King SB, et al. In-hospital cardiac mortality after acute closure after coronary angioplasty: analysis of risk factors from 8207 procedures. $\mathcal{F ~} \mathrm{Am}$ Coll Cardiol 1988;11:211-16.

22 Meier B, Urban P, Dorsaz PA, et al. Surgical standby for coronary balloon angioplasty. $¥ A M A$ 1992;268:741-5.

23 Abbottsmith CW, Topol EJ, George BS, et al. Fate of patients with acute myocardial infarction with patency of the infarct-related vessel achieved with successful thrombolysis versus rescue angioplasty. $\mathcal{F} \mathrm{Am}$ Coll Cardiol 1990;16:770-8.

24 Leung WH, Lau CP. Effects of severity of the residual stenosis of the infarct-related coronary artery on left ventricular dilation and function after acute myocardial infarction [see comments]. F Am Coll Cardiol 1992;20:307infa.

25 Ivanhoe RJ, Weintraub WS, Douglas JS, et al. Percutaneous transluminal coronary angioplasty of chronic total occlusions. Primary success, restenosis, and long-term clinical follow-up. Circulation 1992;85:106-15.

26 Meier B. The hydrophilic guidewire: the poor man's laser for chronic total coronary occlusions for the good and for the bad. Cathet Cardiovasc Diagn 1998;44:91-2.

27 Urban P, Meier B, Finci L, et al. Coronary wedge pressure: a predictor of restenosis after coronary balloon angioplasty. 7 Am Coll Cardiol 1987;10:504-9.

28 Probst P, Baumgartner C, Gottsauner-Wolf $M$. The influence of the presence of collaterals on restenoses after PTCA. Clin Cardiol 1991;14:803-7.

29 Wahl A, Billinger M, Fleisch M, et al. Quantitatively assessed coronary collateral circulation and restenosis following percutaneous revascularisation. Eur Heart $f$ 2000;21:1776-84.

30 Cohen M, Sherman W, Rentrop KP, et al. Determinants of collateral filling observed during sudden controlled coronary artery occlusion in human subjects. $\mathcal{f} \mathrm{Am}$ Coll Cardiol 1989;13:297-303.

31 Piek JJ, Koolen JJ, Hoedemaker G, et al. Severity of single-vessel coronary arterial stenosis and duration of angina as determinants of recruitable collateral vessels during balloon angioplasty occlusion. Am f Cardiol 1991;67: $13-17$.

32 Piek JJ, van Liebergen RA, Koch KT, et al. Clinical, angiographic and hemodynamic predictors of recruitable collateral flow assessed during balloon angioplasty coronary occlusion. $\mathcal{F}$ Am Coll Cardiol 1997;29:275-82.

33 Meier B. Chronic total occlusion. In: Topol EJ, ed. Textbook of interventional cardiology. Philadelphia: WB Saunders, 1994:300-26.

34 Urban P, Meier B, Finci L. Flow reversal in coronary collaterals. Eur Heart f 1987;8:1346-50.

35 Moles VP, Meier B, Urban P, et al. Instantaneous recruitment of reversed coronary collaterals that had been dormant for six years. Cathet Cardiovasc Diagn 1992;26: $148-51$

36 Kaul S. Assessment of coronary microcirculation with myocardial contrast echocardiography: current and future clinical applications. Br Heart f 1995;73:490-5.

37 de Marchi S, Billinger M, Fleisch M, et al. Demonstration of collateral derived myocardial perfusion using quantitative myocardial contrast echocardiography. Heart (in press).

38 Billinger M, Fleisch M, Eberli FR, et al. Is the development of myocardial tolerance to repeated ischemia in humans due to preconditioning or to collateral recruitment? $\mathcal{f} \mathrm{Am}$ Coll Cardiol 1999;33:1027-35.

39 Takeshita A, Koiwaya Y, Nakamura $M$, et al. Immediate appearance of coronary collaterals during ergonovineinduced arterial spasm. Chest 1982;82:319-22.

40 Seiler C, Fleisch M, Billinger M, et al. Physiologically assessed collateral flow and intracoronary growth factor concentrations in patients with 1- to 3-vessel coronary artery disease [letter]. Circulation 2001;103:e22. 